Vol. XXV No $1 \quad 2019$

\title{
CONFLICT MANAGEMENT, A FUNDAMENTAL QUALITY OF THE MILITARY LEADER
}

\author{
Robert STĂNCIULESCU*, Lucian TARNU**, Cristian STĂNCIULESCU** \\ *6Nicolae Bălcescu" Land Forces Academy, Sibiu, Romania \\ **The Police Inspectorate, Sibiu, Romania \\ rstanciulescu@armyacademy.ro, lucian.tarnu@gmail.com, \\ stanciulescu_cristian87@yohoo.com
}

\begin{abstract}
The human resource and the manner in which it is conducted represents for the military organization a prerequisite for achieving success, therefore the concern for improving and maximizing the leadership capacity to lead effectively has always been in the attention of the specialists. The paper presents the essential aspects characterizing the military organization, some of the qualities that the military leader must use in order to manage some of the problems that can arise and endanger the good functioning of the organizations. Among these, conflict management is an extraordinary ability of the military leader, with visible effects in achieving success and representing, in the opinion of many specialists, a cornerstone of successful leadership in the military organization.
\end{abstract}

\section{Keywords: leader, organization, conflict, success, management}

\section{Introduction}

Human activities in general and especially those specific to the military organization require some degree of guidance or coordination in their running in order to ensure the efficiency and successful fulfillment of the assumed objectives. Planning, organizing, conducting, evaluating and control are elements that, if well-managed, ensure performance, and ultimately achieve the goals. At the same time, the complexity of the military system in peacetime, crisis and war situations requires the adoption of a certain leadership style that is adapted to the demands imposed by the existing situation, by the characteristics of the members of the organization and by the forces involved in the activities carried out. This complex process that aims at accomplishing the tasks by the members of the organization, in their sincere desire to perform, with dedication and competence, without any constraints and without applying any coercive means or measures is called leadership.

There are hundreds of definitions of this extremely complex process as a result of the specialists' interest in the study of the field, but all of these definitions have a common feature - a complex process defined in group terms with reference to the honest participation whose goal is the organization's performance. Of course, the one who exercises the leadership is the leader who can be defined as the person who is able within an organization to make its members follow him from pure consciousness, being convinced that he is a role model, the best of them, a man who manages to lead them without applying any means of coercion in successfully accomplishing the objectives of the 
organization. Because of his qualities, the leader inspires and motivates, acquires trust and stimulates the members of the group or organization to which he belongs into sharing his vision. The performance of the organization depends on the way the leader manages to exercise the leadership attributes, so a true leader must always find the best solutions, always adapting to the needs of the organization, to the existing situations and to the people he leads, improving his training, always trying and succeeding in truly being a model to be followed.

\section{Managing conflicts in the military organization}

The individualization of the military organization, with its own system of organization, leadership and hierarchy, which relates to the provisions of the state laws, military regulations, orders and provisions, supposes a continuous concern for identifying and improving the attributes that the leaders of the military hierarchy, and not only them, have to possess in order to organize and coordinate the activities that are carried out in order to successfully fulfill the assumed objectives. The diversity of the events taking place in the military organization, some of them of great intensity, their different interpretation by the members of the organization, as well as the adaptation to the requests imposed by the fulfillment of the objectives are challenges that military leaders have to address with the most effective solutions, considering their impact on the performance of the organization.

\subsection{The military leader and the management of organizations}

Being a military leader is a great challenge. Endowed with formal authority, the military leader can easily turn into a simple manager who only pursues goals, resorting even to constraints, not taking into account that people, even under arms, are social human beings, persons with needs, desires and expectations, whose physical, mental and moral traits must be taken into account by a true leader, a man who inspires, motivates and generates trust. In the military organization, professional leadership is essential for effective leadership. Expressed by the amount and quality of knowledge and skills specific to the system, through the manner of solving all the problems in the activities of the organization, the level of the leader's professional capacity provides him not only with the confirmation of authority conferred by the position he has, but also with the respect and admiration of the members of the organization. Although leaders generally have innate capabilities, these must be enhanced throughout their lives through education, training, and a continuous desire for knowledge and refinement of training, because, as Manfred Ketz de Vries shows, every man has an unused leadership potential, as each of us has a physical potential that we do not use to the full capacity [1].

Analyzing the profile of an effective military leader, we must mention the features and qualities that this needs to have - intelligence, integrity, benevolent attitude, altruism, spiritual openness, courage, or progressive thought are just some of the qualities of a successful leader. But all this is not enough if the leader lacks character and vision, two essential qualities for efficiency. Representing the totality of an individual's psychic and moral attributes, the character is manifested in behavior, in his ideas and actions, in the attitude towards people, at the same time representing the main value side of his personality. Different from temperament, which represents the totality of the physiological and nervous features which an individual is born with, the character is formed throughout life, and it can be improved if the leader manages to see himself exactly as the members of the organization see him. In this way he will identify the aspects that are not in accordance with normality and will try through education and the will to eliminate what is bad and does not produce beneficial effects in the leadership activity. 
Categorically the character of a leader will especially influence the behavior of the members of the organization, whose attitude will be one of respect and admiration, identifying themselves with him and sincerely trying to contribute to the achievement of the goals. Speaking of character, we have to mention two structural components that define it and which constitute a system that allows individuals to be different from one another.

Also known as character traits, the traits belonging to the first part of the character component allow for the differentiation between individuals who, in their turn, are characterized by stability, constancy and pregnancy, which are common and individual. Diligence, punctuality, enthusiasm, energy, firmness, courage, determination, self-composure can be considered positive character traits, while dishonesty, greed, fear, not keeping your promise, or self-defense are considered negative character traits that hinder the leader's activity. Usually the leader is also similar to his subordinates because they see in him a pattern that they will follow. The negative features, such as: pride, lack of principles, encouragement of servility and flattery, and favoritism will be a hindrance to the formation of the moral authority of the leader, and hence to the good life in the organization. A true leader must himself irreproachably respect the military rules and regulations, developing the moral integrity of his subordinates, and being permanently preoccupied with his own integrity. In this way, no matter how strict he is, he will attract the respect and love of the subordinates if, to the same extent, he proves to be just, fair and principled in all that he does, effective leadership supposing to persuade instead of to constrain, to love instead of to hate, to say 'let's do' instead of 'you do'.

The second component is represented by attitudes which represent the characteristics of the individual from the affectivemotivational and volitional point of view. The attitude towards work, the people or even towards their own person can actually contribute to maximizing his chances of approaching a transformational leadership, with particularly productive effects for the organization.

Like character, vision is an essential element for a successful leader. Defined as a path to be followed, a direction or a goal, it is a set of well-defined values that show how the attributes of a performanceoriented leadership are carried out. The way the leader knows how to present his vision, his optimism, his confidence and determination, as well as the strategy he adopts depends on whether the members of the organization identify themselves with the leader and together they manage to translate it into fact. Defined by Gheorghe Aradavoaice as being that person - noncommissioned officer, or commissioned officer - who, having a command position or not, manages by personal qualities, through training, communication, persuasion, conduct, charisma to mobilize the energies of others, to engage them in actions [2], the military leader must combine the attributes of a commander and manager with those of a person with merits and qualities that inspires confidence, stimulates, generates energy, and stands out through tact, modesty and professionalism.

\subsection{Conflict management, a fundamental} quality of the military leader

In order to optimize the psycho-social climate in the military organization, it is necessary to consider the mobilization of the subordinates for the fulfillment of the common goals, as well as the leader's control system, as an important factor influencing the psycho-social climate. For this, leaders should enhance the knowledge of general psychology, military psychology, social psychology, sociology, management science and pedagogy, as a condition of promoting an appropriate leadership style. If the members of the organization have the ability to understand correctly and in time the complexity of the problems which the organization faces, then the leader's tasks to achieve the objectives grow. This is 
because in certain situations a negative interpretation of the solutions found by the leaders can create contrary attitudes among the members of the organization, obviously affecting the organizational performance. Within the organization people can cause difficulties both from the point of view of the formation or manifestation of the personality and from the point of view of professional affirmation. To do this, leaders need to be able to identify the socialization needs of the people in their organization and take measures to prevent the performance of the organization from being affected by certain behaviors. The appearance of conflicts within the organization reduces the organization's productivity because tensions and distrust create discontent, disinterest, and certainly another type of preoccupations. While some people believe that conflict can be used as a tool for change, innovation and progress, leaders need to use all the levers in order to manage these states which surely create problems for the organization. The activity of conflict prevention is of great importance in achieving this objective and this can be done through correct communication and the development of trust relationships between the members of the organization, as well as between the leader and them.

From this point of view, the leader has to ask for the opinions of the members of the organization, listening to them with interest and trying to engage those members with intellectual potential and willingness in the decision-making phenomenon. A basic tenet with beneficial effects in solving conflicts is "Try to understand and then to make yourself understood' [3], which promotes the idea that, if you focus on understanding the ideas of others, it will be much easier to impose your point of view. The leader's path towards performance also requires him to judge and make the right decision when conflicts occur between different parties without benefiting someone, and to show empathy in order to prevent conflicts, which can at any time be the most precious quality of a leader in his activity [4].

There are a number of conflict resolution methods that the leader has to take into account in his work. The method of conflict mediation is one of these, and first of all it involves eliminating the strain or hostile manifestations between the parties to the conflict, as well as identifying the ways of solving that will satisfy parties. Another method at the leader's disposal is avoiding the conflict, which involves the adoption of a leader-coordinated state of passivity, a state that does not solve the conflict but creates the impression that each party involved in the conflict has defeated. Other methods, such as conflict mitigation, compromise, peaceful coexistence, collaboration or negotiation are certainly of great importance, but the military leader must sense the moment of conflict emergence and take all the measures to prevent it from breaking out.

\section{Conclusions}

The military leader's activity for conflict prevention and resolution is a complex and very important activity in achieving performance by the military organization. Among the qualities and traits that he needs to possess, an essential role in this activity is the communication that must represent the safe weapon of the leader in his work to identify the causes of conflicts. Conflict prevention and resolution in general and especially in the military organization has visible effects in the organization's performance, which is why this is in the attention of the specialists and represents an activity generating positive effects and outstanding results if it is well-managed.

\section{References}

[1] Manfred Ketz de Vries, Leadership, Arta şi măiestria de a conduce, Editura Codex Publishing House, Bucharest, 2010 
[2] Gheorghe Aradavoaice, Stresul psihic în lupta armată, Editura AISM, Pro Transilvania Publishing House, Bucharest, 1993

[3] Steven Covey, Eficienţa în şapte trepte, Leader Publishing House, Bucharest, 2002

[4] Cristea Dumitru, Tratat de psihologie socială, Bucharest, 2001 